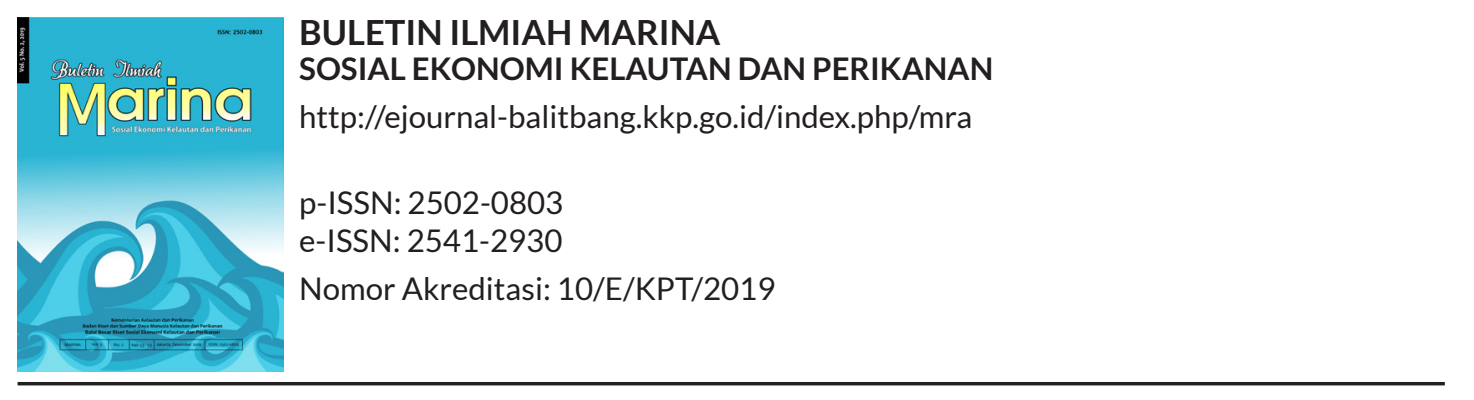

\title{
IZIN LOKASI PERAIRAN SEBAGAI SUMBER PENERIMAAN NEGARA BUKAN PAJAK (PNBP): Studi Kasus Wisata Bahari di Pulau Maratua
}

\section{The Water Location Permit as the Non-Tax State Revenue (NTSR): Case Study on Marine Tourism in Maratua Island}

\author{
*Didit Eko Prasetiyo1, Uswatun Chasanah², Muhandis Sidqi", \\ Budi Muhammad Ruslan', Gustiawirman ${ }^{3}$, dan Suraji ${ }^{1}$ \\ ${ }^{1}$ Direktorat Perencanaan Ruang Laut, Kementerian Kelautan dan Perikanan \\ JI. Medan Merdeka Timur Nomor 16 Jakarta Pusat, Indonesia \\ 2Universitas Pamulang
}

Jl. Surya Kencana No.1, Kec. Pamulang, Kota Tangerang Selatan, Banten 15417, Indonesia

${ }^{3}$ Sekretariat Direktorat Jenderal Pengelolaan Ruang Laut, Kementerian Kelautan dan Perikanan JI. Medan Merdeka Timur Nomor 16 Jakarta Pusat, Indonesia

Diterima tanggal: 10 April 2020 Diterima setelah perbaikan: 21 Mei 2020

Disetujui terbit: 26 Juni 2020

\begin{abstract}
ABSTRAK
Kegiatan wisata bahari di Pulau Maratua memiliki beberapa permasalahan, yaitu kurangnya pemahaman pelaku usaha mengenai kewajiban izin lokasi perairan, kurangnya infrastruktur pendukung wisata bahari, dan rendahnya nilai penerimaan negara yang diperoleh oleh Kementerian Kelautan dan Perikanan (KKP). Penelitian ini bertujuan untuk mengetahui kontribusi izin lokasi perairan kegiatan wisata bahari di Kawasan Strategis Nasional Tertentu (KSNT) Pulau Maratua terhadap PNBP yang diterima oleh KKP. Penelitian dilakukan di seluruh perairan KSNT Pulau Maratua pada bulan April 2019 sampai dengan bulan Maret 2020 dengan pendekatan kualitatif. Pengumpulan data diperoleh dari 15 (lima belas) pelaku usaha wisata bahari. Data primer dikumpulkan melalui wawancara untuk menggali informasi mengenai kewajiban izin lokasi perairan, kegiatan wisata bahari dan pembayaran PNBP, sedangkan data sekunder didapatkan dari kepustakaan dengan mempelajari literatur, peraturan perundang-undangan, dan laporan yang berhubungan dengan penelitian ini. Analisis data yang digunakan adalah metode deskriptif kualitatif. Hasil penelitian didapatkan bahwa kegiatan yang dilakukan KKP untuk meningkatkan pemahaman pelaku usaha dengan melakukan sosialisasi perizinan pemanfaatan ruang laut, pengambilan keterangan, dan pembukaan loket pelayanan perizinan belum mampu menggerakkan seluruh pelaku usaha wisata bahari untuk mengajukan izin lokasi perairan. Selama kurun waktu 1 (satu) tahun hanya $40 \%$ atau sebanyak 6 (enam) pelaku usaha dari total 15 (lima belas) yang telah mengajukan permohonan dan mendapatkan izin lokasi perairan dari Menteri Kelautan dan Perikanan dengan nilai PNBP sebesar Rp238.200.000,00. Oleh karena itu, untuk meningkatkan kontribusi PNBP, perlu dilakukan sosialisasi dan pembinaan yang lebih intensif, perbaikan inovasi dan kualitas pelayanan perizinan, peningkatan kompetensi sumber daya manusia, pengelolaan PNBP, menetapkan target dan optimalisasi realisasi PNBP, dan pemberian sanksi.
\end{abstract}

Kata Kunci: kontribusi; izin lokasi perairan; wisata bahari; Pulau Maratua; PNBP

\section{ABSTRACT}

Marine tourism on Maratua Island has been suffered from several problems, including less understanding of water location permit, lack of adequate infrastructure of marine tourism, and small amount of non-tax state revenue (NTSR) earned by Ministry for Marine Affairs and Fisheries (MMAF). 
This study aimed to determine the contribution of National Strategic Spesific Area (NSSA) permit to NTSR earned by MMAF. The study was conducted on all waters of NSSA in Maratua Island from April 2019 to March 2020 with a qualitative approach. Primary data were collected through interviews from 15 (fifteen) marine tourism entrepreneurs to explore more information on the compulsory of location permit, marine tourism activities and NTSR. Secondary data were collected from literature study, regulations, and relevant reports. Data were analyzed with qualitative descriptive method. The results found that MMAF efforts to provide more understanding on water location permit, information gathering, and permit offices have not been able to encourage all marine tourism entrepreneurs to apply water location permit. There were only $40 \%$ in 1 (one) year or 6 (six) from a total of 15 (fifteen) entrepreneurs who submitted application and obtained water location permit from the MMAF.Total amount of NTSR collected from those application was IDR238,200,000.00. Therefore, in order to raise this revenue, it is necessary to provide more intensive assistance, innovation, better quality of permit services, human resource empowerment, management of NTSR, optimum target and expenditure of NTSR, and punishment for breaches of permit regulation.

Keywords: contribution; water location license; marine tourism; Maratua Island; non-tax state revenue

\section{PENDAHULUAN}

Penerimaan negara terdiri dari penerimaan perpajakan dan penerimaan bukan pajak. Penerimaan bukan pajak memiliki 4 (empat) kategori, yaitu penerimaan sumber daya alam (SDA), Pendapatan dari Kekayaan Negara yang dipisahkan, Penerimaan Negara Bukan Pajak (PNBP) lainnya, dan pendapatan Badan Layanan Umum. Menurut data Badan Pusat Statistik (2020), realisasi PNBP mengalami penurunan dari sejumlah Rp128.574.000.000,00 (tahun 2018) menjadi Rp103.781.100.000,00 (tahun 2019). $\mathrm{Hal}$ ini menunjukkan penurunan PNBP sebesar Rp24.792.900.000,00 atau sebesar 19,28\%.

Ada beberapa sektor potensial yang sebenarnya bisa dioptimalkan oleh pemerintah untuk peningkatan PNPB. Sektor kelautan dan perikanan merupakan salah satu sektor potensial bagi negara untuk meningkatkan PNBP, tetapi sampai saat ini belum dikelola secara optimal oleh Kementerian Kelautan dan Perikanan (KKP) sebagai instansi pengelola PNBP sektor kelautan dan perikanan. Sumber PNBP yang dapat dioptimalkan KKP berasal dari Direktorat Jenderal Perikanan Tangkap (DJPT), Direktorat Jenderal Perikanan Budidaya (DJPB), Direktorat Jenderal Penguatan Daya Saing Produk Kelautan dan Perikanan (DJPDS), Direktorat Jenderal Pengelolaan Ruang Laut (DJPRL), Badan Riset dan Sumber Daya Manusia Kelautan dan Perikanan (BRSDM), serta Badan Karantina Ikan, Pengendalian Mutu, dan Keamanan Hasil Perikanan (BKIPM). Pengelolaan PNBP KKP diatur dalam Peraturan Pemerintah Nomor 75 Tahun 2015 tentang jenis dan tarif atas jenis penerimaan negara bukan pajak yang berlaku pada Kementerian Kelautan dan Perikanan (KKP, 2018).

Pembahasan mengenai PNBP KKP banyak dilakukan pada sektor perikanan, utamanya bidang perikanan tangkap dan perikanan budi daya. Jenis PNBP pada DJPT berupa pungutan hasil perikanan atas izin penangkapan ikan untuk kapal penangkap ikan dan/atau kapal pendukung operasi penangkapan ikan baru atau perpanjangan dan jenis PNBP pada DJPB berupa pungutan pengusahaan perikanan bidang pembudi daya ikan. Realisasi PNBP SDA perikanan tahun 2009-2015 belum mampu meningkat signifikan. Selama periode tersebut, realisasi PNBP SDA perikanan rata-rata hanya sebesar Rp158.000.000.000,00 atau lebih rendah dibandingkan dengan realisasi periode antara tahun 2016 - 2018 dengan capaian ratarata sebesar Rp433.000.000.000,00 (Panjaitan, Mujiburrahman \& Effendi, 2019).

Sampai dengan saat ini, PNBP KKP di sektor kelautan belum banyak dikaji terutama mengenai perizinan di bidang pengelolaan ruang laut, padahal hal ini dapat menjadi peluang baru sebagai sumber PNBP di sektor kelautan dan perikanan. Salah satu jenis PNBP sektor kelautan adalah izin lokasi perairan yang merupakan dasar untuk penerbitan izin usaha sektor lain yang memanfaatkan ruang laut secara menetap. Pemanfaatan ruang laut secara menetap ini biasanya banyak dilakukan untuk kegiatan wisata bahari.

Pemanfaatan ruang laut secara menetap di Pulau Maratua, Provinsi Kalimantan Timur, marak untuk kegiatan wisata bahari seperti 
pembangunan resor di laut sehingga berpotensi dalam meningkatkan realisasi PNBP dari izin lokasi perairan. Kegiatan wisata bahari di Pulau Maratua didukung oleh Kementerian Pariwisata dengan ditetapkannya Peraturan Pemerintah Nomor 50 Tahun 2011 tentang Rencana Induk Pembangunan Pariwisata Nasional (RIPPARNAS) dengan ruang lingkup Kawasan Strategis Pariwisata Nasional (KSPN) Derawan-Sangalaki berada di Kecamatan Derawan dan Kecamatan Maratua, Kabupaten Berau, Provinsi Kalimantan Timur (Kementerian Pariwisata, 2018).

Meskipun Peraturan Pemerintah Nomor 75 Tahun 2015 tentang jenis dan tarif atas jenis penerimaan negara bukan pajak yang berlaku di KKP telah ditetapkan sejak 5 (lima) tahun yang lalu, namun izin lokasi perairan kegiatan wisata bahari di Kawasan Strategis Nasional Tertentu (KSNT) Pulau-Pulau Kecil Terluar (PPKT) Pulau Maratua baru bisa diterbitkan dan dipungut PNBP pada tahun 2020.

Selain itu, kegiatan wisata bahari di Pulau Maratua memiliki beberapa permasalahan, yaitu kurangnya pemahaman pelaku usaha mengenai kewajiban izin lokasi perairan, kurangnya infrastruktur pendukung wisata bahari, seperti ketersediaan air bersih, listrik, dermaga penyeberangan/jetty, dan rendahnya nilai penerimaan negara yang didapatkan oleh KKP. Penelitian ini dilakukan untuk mengkaji kontribusi izin lokasi perairan kegiatan wisata bahari di KSNT Pulau Maratua yang merupakan kewenangan Menteri Kelautan dan Perikanan yang dapat dijadikan sumber PNBP oleh KKP.
Penelitian ini menggunakan pendekatan kualitatif dengan penelitian yang dilakukan bersifat deskriptif untuk mengetahui dan menggambarkan mengenai kontribusi izin lokasi perairan kegiatan wisata bahari di Pulau Maratua terhadap PNBP yang didapatkan. Penelitian dilakukan di Pulau Maratua, Kabupaten Berau, Provinsi Kalimantan Timur pada bulan April 2019 sampai dengan Maret 2020 (Gambar 1).

Penelitian ini menggunakan sampel informan kunci sebanyak 15 (lima belas) pelaku usaha wisata bahari diambil seluruhnya untuk dijadikan sebagai sampel dan sumber data. Data primer diperoleh melalui wawancara untuk menggali informasi mengenai kewajiban izin lokasi perairan, kegiatan wisata bahari dan pembayaran PNBP, sedangkan data sekunder didapatkan dari kepustakaan dengan mempelajari literatur, peraturan perundang-undangan dan laporan yang berhubungan dengan penelitian ini.

Analisis data yang digunakan adalah metode deskriptif kualitatif, yaitu suatu teknik yang menguraikan, menggambarkan, dan mempresentasikan arti dari data-data yang terkumpul dengan memberikan perhatian dan merekam aspek situasi yang diteliti, sehingga dapat memperoleh gambaran secara umum dan menyeluruh tentang keadaan sebenarnya (Sekaran, 2011). Data hasil penelitian diperoleh dari wawancara dan kepustakaan dikumpulkan, diklasifikasikan, serta diolah dan dianalisis untuk menghasilkan informasi bagi pemecahan masalah.

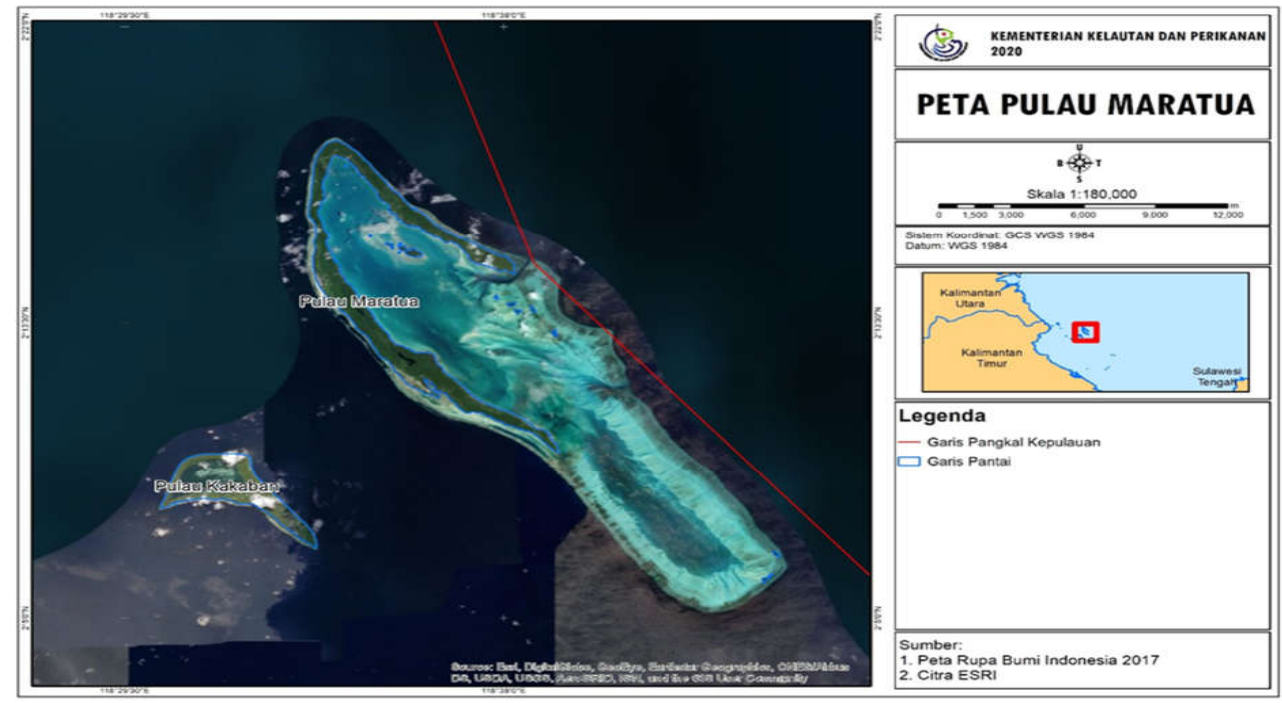

Gambar 1. Peta Pulau Maratua.

Sumber: Direktorat Perencanaan Ruang Laut, 2020 


\section{GAMBARAN UMUM PNBP DI KKP}

DJPRL mempunyai tugas dan fungsi untuk mengelola PNBP kategori Non Sumber Daya Alam. Pendapatan DJPRL periode 31 Desember 2017 sebesar Rp12.769.931.890,00 sedangkan dan 31 Desember 2018 sebesar Rp16.236.285.129,00. Secara keseluruhan, PNBP tahun 2018 mengalami kenaikan sebesar $27,14 \%$ jika dibandingkan tahun 2017 dengan sebagaian besar pendapatan berasal dari perizinan lainnya terkait reklamasi (Kementerian Kelautan dan Perikanan, 2018). Izin lokasi perairan termasuk dalam pendapatan perizinan lainnya, namun belum terdapat rencana target dan realisasi dari PNBP ini. Menurut Direktorat Jenderal Pengelolaan Ruang Laut (2020), peningkatan kontribusi PNBP izin lokasi perairan akan dilakukan dengan penambahan Indikator Kinerja Utama (IKU) mengingat telah terbit Peraturan Menteri Kelautan dan Perikanan Nomor 24/PERMEN$\mathrm{KP} / 2019$ tentang tata cara pemberian izin lokasi perairan dan izin pengelolaan perairan di wilayah pesisir dan pulau-pulau kecil.

\section{Target dan Realisasi PNBP}

Dalam mengelola PNBP perlu ditetapkan target dan realisasinya. Praktek pengelolaan PNBP dijelaskan oleh Angraini, Amir, \& Yusnita (2018) bahwa tren pertumbuhan target PNBP pada Satuan Kerja (Satker) Kantor Pertanahan Kabupaten Parigi Moutong selama periode tahun 2011- 2015 mengalami fluktuasi. Hal ini terlihat bahwa proses perencanaan target PNBP Satker belum direncanakan secara matang dan penuh pertimbangan serta tidak melalui proses evaluasi. Perencanaan yang tidak melibatkan Satker dalam proses penyusunan target PNBP menyebabkan rendahnya motivasi Satker untuk mencapai target sehingga realisasi penerimaan PNBP tidak tercapai.

Demikian halnya dengan hasil penelitian di Taman Nasional Bali Barat (TNBB) terdapat peningkatan jumlah PNBP dari tahun 2012 sampai dengan 2016 yang menunjukkan kinerja yang sangat baik dari pihak TNBB dalam mengoptimalkan penerimaan dengan selalu tercapainya target yang ditentukan dengan realisasi yang dihasilkan (Budi \& Handayani, 2019). Penelitian tersebut memberikan pemahaman bahwa dalam mengelola PNBP diperlukan acuan mulai tahap perencanaan, pelaksanaan dan penatausahaan, serta pengawasan dan pelaporan agar realisasi PNBP dapat dilakukan sesuai dengan target yang telah ditetapkan.

\section{Pemberian Izin Lokasi Perairan}

Setiap pemanfaatan ruang dari sebagian perairan pesisir dan pulau-pulau kecil secara menetap wajib memiliki izin lokasi dengan luasan dan waktu tertentu. Namun, izin lokasi tidak dapat diberikan pada semua wilayah karena terdapat zona yang tidak diperbolehkan untuk dimanfaatkan oleh individu atau kelompok, yaitu zona inti di kawasan konservasi, alur laut, kawasan pelabuhan, dan pantai umum (Astuti, Budisusanto, Pratomo \& Sidqi, 2018). Izin lokasi perairan diberikan kepada pelaku usaha yang terdiri atas setiap orang, baik orang perseorangan, korporasi, dan koperasi. Izin lokasi perairan merupakan dasar untuk penerbitan izin usaha di sektor lain. Makna setiap pemanfaatan ruang cukup luas, meliputi seluruh kegiatan yang bersifat menetap, seperti pembangunan resor di laut yang termasuk kegiatan wisata bahari.

\section{Wisata Bahari}

Wisata bahari merupakan aktivitas rekreasi yang meliputi perjalanan jauh dari suatu tempat tinggal menuju lingkungan laut. Lingkungan laut adalah perairan yang bergaram dan dipengaruhi oleh pasang surut (Orams, 1999). Perencanaan penggunaan ruang laut di Pulau Maratua diketahui terdapat 7 (tujuh) zona dengan 9 (sembilan) sub zona, dimana sub zona ekowisata mempunyai luas $18.608,377 \mathrm{Ha}$. Kondisi eksisting di Pulau Maratua terdapat objek wisata bahari berupa resor/penginapan wisata yang kebanyakan terdapat di Desa Payung - Payung (Sidqi, Suharyanto, Astuti, \& Ardarini, 2018).

\section{KARAKTERISTIK PULAU MARATUA}

Secara geografis, Pulau Maratua merupakan pulau kecil berpenduduk yang terletak di Laut Sulawesi dengan Titik Dasar (TD.039) dan Titik Referensi (TR.039). Secara geografis, Pulau Maratua terletak di sebelah timur Pulau Kalimantan, tepatnya pada posisi $02^{0} 15^{\prime} 12^{\prime \prime}$ LU dan 118 38'41" BT. Pulau Maratua memiliki 4 kampung, yaitu Kampung Bohe Silian, Alulu, Teluk Harapan, dan Payung-payung (Direktorat Pendayagunaan Pesisir dan Pulau-Pulau Kecil, 2020).

Berdasarkan Badan Perencana Penelitian dan Pengembangan Kabupaten Berau (2019), 
Kecamatan Maratua merupakan wilayah dengan kepadatan penduduk paling rendah dibandingkan dengan kecamatan lain di Kabupaten Berau dengan jumlah penduduk sebanyak 3.927 jiwa dan kepadatan penduduk sebesar 0,95 jiwa/ $\mathrm{km}^{2}$. Pulau Maratua berbatasan langsung dengan perairan negara Filipina dan telah dikenal secara internasional sebagai daerah tujuan wisata dengan pantai dan alam bawah lautnya memiliki panorama yang indah.

Kondisi alam bawah laut Pulau Maratua memiliki keanekaragaman ikan yang cukup tinggi, yaitu sebanyak 144 spesies ikan karang dari suku Caesionidae, Pomacentridae, Serranidae, Labridae, Chaetodontidae, Acanthuridae, Scaridae, Zanclidae, Siganidae, dan berbagai suku lainnya. Terumbu karang didominasi oleh marga Acropora, Montipora, Porites, Seriatopora, dan Pocillopora (Idris, Prastowo, \& Rahmat, 2019). Padang lamun terdiri dari 8 spesies, yaitu Halodule univervis, pinifolia, Cyamodocea rotundata, Syringodium isoetifolium, Enhalus acoroides, Thalassia hemprichii, Halophila ovata, dan Halophila ovalis, serta perairan Pulau Maratua banyak terdapat lumba-lumba dan merupakan tempat migrasi keluarga paus sperm (Mellawati, Fepriadi, Yarianto, \& Laddade, 2010). Tingginya keanekaragaman hayati laut perairan Pulau Maratua merupakan daya tarik bagi pelaku usaha untuk melakukan investasi wisata bahari.

\section{Kegiatan Wisata Bahari}

Pemanfaatan ruang laut di Pulau Maratua menurut Direktorat Perencanaan Ruang Laut (2019), terdiri dari kegiatan pelabuhan, dermaga perusahaan, dermaga kampung (untuk umum), dermaga terapung (untuk umum), wisata bahari, pemukiman masyarakat, jembatan, dan keramba jaring apung. Ada dua jenis pemanfaatan ruang laut yang dominan di Pulau Maratua; yaitu pemukiman masyarakat dan wisata bahari.

Pada periode April 2019 sampai dengan Maret 2020 diketahui sebanyak 15 (lima belas) pelaku usaha yang melakukan pembangunan sarana wisata bahari dan fasilitas pendukungnya di laut (Tabel 1).

Menurut Tabel 1, pelaku usaha memanfaatkan ruang laut secara menetap dengan membangun kamar, restoran, ruang pertemuan, diving center, jembatan, dan jetty. Dari beberapa pemanfaatan tersebut, paling banyak adalah jetty karena di lokasi penelitian memiliki privatisasi yang tinggi sehingga apabila ada tamu yang akan datang dapat menggunakan kapal speed boat langsung menuju resort tanpa melalui pelabuhan umum yang disediakan oleh pemerintah. Menurut Yustinaningrum (2017), wisata bahari merupakan suatu kegiatan pengembangan kegiatan pariwisata dengan mengedepankan aspek kelautan (bahari) sebagai atraksi utama, tidak

Tabel 1.Pelaku Usaha Kegiatan Wisata Bahari yang Memanfaatkan Ruang Laut di Pulau Maratua.

\begin{tabular}{|c|c|c|}
\hline Pelaku Usaha & Kegiatan & $\begin{array}{l}\text { Pembangunan Sarana Wisata Bahari } \\
\text { dan Fasilitas Pendukungnya }\end{array}$ \\
\hline PT Pondok Wisata & Wisata Bahari & Restoran, jetty \\
\hline PT Maratua Paradise & Wisata Bahari & Kamar, restoran, diving center, jembatan, jetty \\
\hline PT Noah Maratua Resor & Wisata Bahari & Restoran, diving center, jetty \\
\hline PT Pratasaba Apta Astama & Wisata Bahari & $\begin{array}{l}\text { Restoran, ruang pertemuan, diving center, } \\
\text { jembatan, jetty }\end{array}$ \\
\hline PT Maratua Island Diving Resort & Wisata Bahari & Restoran, diving center, jembatan, jetty \\
\hline PT Jade Homestay & Wisata Bahari & Jembatan, jetty \\
\hline PT Surga Hijau Lestari & Wisata Bahari & Diving center, jembatan, jetty \\
\hline PT Maratua Camp & Wisata Bahari & Kamar, jembatan, jetty \\
\hline PT Maratua Seaview Resort & Wisata Bahari & Diving center, jembatan, jetty \\
\hline PT Paradina Adya Sandika & Wisata Bahari & Restoran, jetty \\
\hline PT Tanjung Dewata Resort & Wisata Bahari & Diving center, jetty \\
\hline Virgin Cocoa Tropical Hideaway Island & Wisata Bahari & Jembatan, jetty \\
\hline Nunukan Island Resort & Wisata Bahari & Jembatan, jetty \\
\hline PT Maratua Nusa Sentosa & Wisata Bahari & Kamar, jembatan, jetty \\
\hline PT Nabucco Island & Wisata Bahari & Diving center, jembatan, jetty \\
\hline
\end{tabular}


hanya untuk pemanfaatan ruang laut secara menetap, seperti peristirahatan (resort), namun dapat dikembangkan dalam konsep wisata bahari, seperti rekreasi pantai dan laut, wisata selam (diving) dan snorkling, selancar, jet ski, wisata ekosistem, wisata nelayan, wisata pulau, wisata pendidikan, wisata pancing, serta wisata satwa.

\section{IZIN LOKASI PERAIRAN}

\section{Landasan Hukum}

Ketentuan mengenai kewenangan, tata cara pemberian, jenis, tarif, dan pungutan PNBP izin lokasi perairan kegiatan wisata bahari di KSNT Pulau Maratua adalah sebagai berikut.

1. Undang-Undang Nomor 1 Tahun 2014 Tentang Perubahan Atas Undang-Undang Nomor 27 Tentang Pengelolaan Wilayah Pesisir dan Pulau-Pulau Kecil mengatur mengenai pemanfaatan ruang dari sebagian perairan pesisir secara menetap wajib memiliki izin lokasi perairan dan Menteri Kelautan dan Perikanan berwenang menerbitkan izin lokasi perairan di KSNT berdasarkan pada Rencana Zonasi. Menurut Priyono (2016), izin adalah suatu persetujuan dari penguasa berdasarkan peraturan perundang-undangan. Dengan demikian, peraturan perundang-undangan pada prinsipnya memuat larangan dan persetujuan yang merupakan dasar pengecualian (izin).

2. Rencana Zonasi sebagai dasar Menteri Kelautan dan Perikanan menerbitkan izin lokasi perairan adalah Peraturan Menteri Kelautan dan Perikanan Nomor 4/PERMEN-KP/2018 tentang rencana zonasi kawasan strategis nasional tertentu Pulau Maratua dan Pulau Sambit di Provinsi Kalimantan Timur Tahun 2018-2037. Pengelolaan ruang laut terdiri dari perencanaan, pemanfaatan, pengawasan dan pengendalian pemanfaatan ruang laut, dimana rencana zonasi merupakan bagian dari perencanaan. Menurut Ehler, Zaucha, \& Gee (2019), perencanaan tata ruang laut/ maritim adalah tentang mengelola kegiatan manusia dalam alokasi ruang dan waktu untuk mendapatkan tujuan dan hasil berupa ekologi, ekonomi dan sosial.

3. Pengaturan mengenai subyek hukum, persyaratan, dan tata cara permohonan izin lokasi perairan diatur dalam Peraturan Menteri Kelautan dan Perikanan Nomor 24/PERMENKP/2019 tentang tata cara pemberian izin lokasi perairan dan izin pengelolaan perairan di wilayah pesisir dan pulau-pulau kecil. Izin lokasi perairan menjadi dasar untuk pemberian izin usaha sektor lain yang menggunakan perairan pesisir secara menetap. Sugiarto (2017) menyatakan bahwa untuk pelaksanaan izin pemanfaatan ruang, Pemerintah Kabupaten Sidoarjo menerbitkan Peraturan Bupati Nomor 20 Tahun 2009 Tentang Tata Cara Penerbitan Izin Lokasi dan Persetujuan Pemanfaatan Ruang di Kabupaten Sidoarjo.

4. PNBP izin lokasi perairan dikelola Direktorat Jenderal Pengelolaan Ruang Laut yang diatur dalam Peraturan Pemerintah Nomor 75 Tahun 2015 tentang jenis dan tarif atas jenis penerimaan negara bukan pajak yang berlaku pada Kementerian Kelautan dan Perikanan, dimana untuk tarif izin lokasi perairan kegiatan Wisata Bahari, dengan kategori lokasi: di dalam Rencana Induk Pembangunan Kepariwisataan Nasional (RIPPARNAS), sebesar Rp30.000.000,00 per ha per 2 tahun (Rp/ha/2 tahun) dan di luar RIPPARNAS, sebesar Rp15.000.000,00 per ha per 2 tahun (Rp/ha/2 tahun).

Kewajiban memiliki izin lokasi perairan berawal dari adanya Putusan Nomor 3/PUUVIII/2010 bahwa pengelolaan perairan pesisir dan pulau-pulau kecil melalui mekanisme pemberian Hak Pengusahaan Perairan Pesisir (HP-3) mengurangi hak penguasaan negara dan dinyatakan bertentangan dengan UndangUndang Dasar Negara Republik Indonesia Tahun 1945 dan tidak mempunyai kekuatan hukum mengikat. Oleh karena itu, tanggung jawab negara atas pengelolaan wilayah pesisir dan pulaupulau kecil dalam bentuk penguasaan kepada pihak lain (perseorangan atau swasta) melalui mekanisme perizinan. Izin lokasi perairan yang telah diterbitkan adalah bersifat final dan mengikat (binding). Hal ini berbeda dengan hukum agraria bahwa izin lokasi sebagai upaya perolehan hak atas tanah dalam penyelenggaraan pembangunan perumahan yang sesuai dengan Undang-Undang Nomor 1 Tahun 2011 Tentang Perumahan dan Kawasan Permukiman (Yunia, 2016).

Rencana Zonasi KSNT pada tahun 2018, KKP sebaiknya segera memproses dan menerbitkan izin lokasi perairan sebagai bentuk pelaksanaan fungsi pengaturan dan pengendalian yang dimiliki oleh pemerintah. Selanjutnya, pemerintah dapat memperoleh PNBP dengan 
memperkenankan pemegang izin untuk melakukan tindakan atau kegiatan tertentu yang sebenarnya dilarang demi memperhatikan kepentingan umum (Priyono, 2016).

\section{Tata Cara Permohonan Izin Lokasi Perairan}

Menurut Sutendi (2019), komitmen adalah pernyataan pelaku usaha untuk memenuhi persyaratan izin usaha dan/atau izin komersial atau operasional. Dalam rangka memenuhi komitmennya berdasarkan izin usaha dan izin komersial atau operasional, terdapat beberapa perizinan yang harus dipenuhi oleh pelaku usaha, yaitu:

1. izin lokasi,

2. izin lokasi perairan,

3. izin lingkungan, dan/atau

4. izin mendirikan bangunan.

Persyaratan dan prosedur permohonan izin lokasi perairan kegiatan wisata bahari di KSNT Pulau Maratua dilakukan dengan tahapan sebagaimana infografis yang disampaikan Gambar 2 dengan tata cara berikut.

1. Pelaku usaha mendapatkan Nomor Induk Berusaha (NIB) secara online melalui sistem Online Single Submission (OSS).

2. Pelaku usaha menyampaikan permohonan izin lokasi perairan beserta proposal secara offline kepada Menteri Kelautan dan Perikanan melalui PTSP. Adapun sistematika proposal, meliputi: pakta integritas, latar belakang, maksud dan tujuan, lokasi administrasi, dan posisi geografis, koordinat geografis dan luas, peta lokasi dan site plan, kedalaman (layer) yang akan dimanfaatkan, data kondisi terkini lokasi, serta rencana investasi usaha.

3. KKP melakukan verifikasi sebagai pertimbangan persetujuan atau penolakan.

4. Menteri Kelautan dan Perikanan menerbitkan persetujuan atau penolakan izin lokasi perairan melalui PTSP.

5. Sistem OSS menerima notifikasi persetujuan atau penolakan izin lokasi perairan dan menyampaikan kepada pelaku usaha.

Persyaratan yang dijelaskan pada Gambar 2 menunjukkan bahwa izin lokasi perairan merupakan kategori izin dasar atau izin di awal, karena tidak mempersyaratkan perizinan lainnya dalam permohonannya dan merupakan dasar untuk penerbitan izin usaha sektor lain, seperti izin pengelolaan perairan, izin pelaksanaan reklamasi, tanda daftar usaha pariwisata, surat izin usaha perikanan, izin usaha pertambangan, izin membangun bangunan dan/ atau Instalasi di laut, izin terminal khusus, serta digunakan sebagai dokumen kesesuaian ruang atau zonasi yang dipersyaratkan dalam perizinan sektor lain.

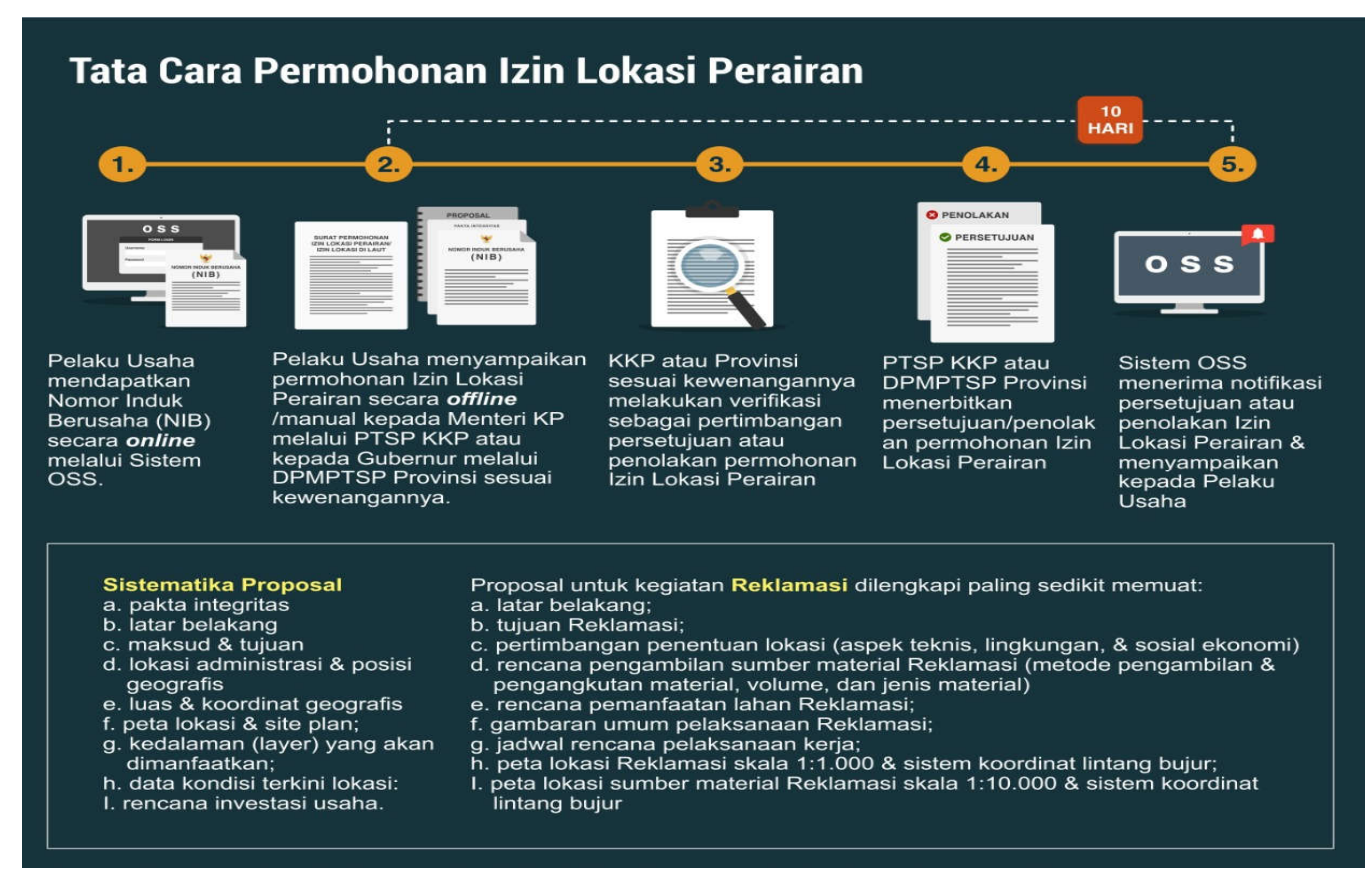

Gambar 2. Tata Cara Pemberian Izin Lokasi Perairan.

Sumber: Direktorat Jenderal Pengelolaan Ruang Laut, 2019 
Lebih lanjut mengenai prosedur permohonan, pelaku usaha harus menyampaikan secara offline langsung ke PTSP di Gedung Mina Bahari IV, Lantai 1. Kewajiban datang langsung ke PTSP kurang efektif dan sistem pelayanan berusaha terintegrasi secara elektronik atau OSS yang semua pengurusan izin dilakukan dengan cara yang lebih mudah, cepat, tepat, dan efisien (Robby \& Tarwini, 2019). Semangat dari sistem OSS terkait kemudahan perizinan berusaha diperlukan untuk meningkatkan iklim investasi di Indonesia, namun tanpa melupakan prinsip izin sebagai instrumen pengendali masyarakat yang diwujudkan melalui pengawasan di daerah (Arrum, 2019).

\section{Permohonan Izin Lokasi Perairan Kegiatan Wisata Bahari}

Pada tahun 2019-2020 terdapat 7 (tujuh) pelaku usaha yang sudah memohonkan izin lokasi perairan dan sebanyak 8 (delapan) pelaku usaha lainnya belum memohonkan (Tabel 2). Hal ini menunjukkan pelaku usaha yang belum memohonkan izin lokasi perairan sebesar 53\%, padahal telah dilakukan pemanfaatan ruang laut secara menetap berupa pembangunan sarana wisata bahari dan fasilitas pendukungnya. Izin lokasi perairan merupakan kontrol agar pemanfaatan ruang laut dapat sesuai dengan Rencana Zonasi KSNT Pulau Maratua, sebagaimana disampaikan Supriyatno dan Budi (2009) bahwa perizinan adalah salah satu instrumen pengendalian pemanfaatan ruang yang bertujuan untuk menjaga agar pemanfaatan ruang dapat berlangsung sesuai dengan fungsi ruang yang telah ditetapkan dalam perencanaan ruang (rencana tata ruang). Oleh karena itu, izin lokasi perairan idealnya dimiliki oleh pelaku usaha sebelum melaksanakan pemanfaatan ruang laut.

KKP mengeluarkan kebijakan yang memberikan kemudahan kepada pelaku usaha wisata bahari untuk melakukan pengurusan izin untuk mendorong para pelaku usaha mengajukan permohonan izin lokasi perairan. Djou (2013) yang merekomendasikan kepada Pemerintah Kabupaten Ende bahwa dalam mengelola potensi-potensi wisata bahari yang ada harus mengeluarkan kebijakan yang memberikan kesempatan dan kemudahan kepada pelaku pariwisata untuk dapat masuk ke dalam kawasan wisata bahari agar dapat memulai usahanya. Kebijakan yang dilakukan adalah dengan mempermudah pengurusan izin usaha dan izin mengelola kawasan wisata bahari, termasuk kebijakan yang terkait dengan penataan ruang dan perlindungan terhadap lingkungan.

Tabel 2. Daftar Pelaku Usaha yang Memohonkan Izin Lokasi Perairan Periode April 2019 sampai dengan Maret 2020.

\begin{tabular}{lcc}
\multicolumn{1}{c}{ Pelaku Usaha } & Memohonkan Izin Lokasi Perairan \\
\cline { 2 - 3 } & Sudah & Belum \\
\hline PT Pondok Wisata & - & - \\
PT Maratua Paradise & $\sqrt{ }$ & - \\
PT Noah Maratua Resor & $\sqrt{ }$ & - \\
PT Pratasaba Apta Astama & - & $\sqrt{ }$ \\
PT Maratua Island Diving Resort & $\sqrt{ }$ & $\sqrt{ }$ \\
PT Jade Homestay & - & - \\
PT Surga Hijau Lestari & - & $\sqrt{ }$ \\
PT Maratua Camp & $\sqrt{ }$ & $\sqrt{ }$ \\
PT Maratua Seaview Resort & - & $\sqrt{ }$ \\
PT Paradina Adya Sandika & - & - \\
PT Tanjung Dewata Resort & - & $\sqrt{ }$ \\
Virgin Cocoa Tropical Hideaway Island & $\sqrt{ }$ & $\mathbf{8}$ \\
Nunukan Island Resort & - & $\mathbf{7}$ \\
PT Maratua Nusa Sentosa & &
\end{tabular}

Sumber: Pelayanan Terpadu Satu Pintu DJPRL KKP, 2020 


\section{PEMAHAMAN PELAKU USAHA WISATA BAHARI TERHADAP IZIN LOKASI PERAIRAN}

Pemberian pemahaman kepada pelaku usaha mengenai kegiatan wisata bahari dan kewajiban izin lokasi perairan, dilakukan oleh KKP kepada organisasi perangkat daerah (OPD), masyarakat, dan pelaku usaha di Pulau Maratua, dengan kegiatan sebagai berikut.

1. Sosialisasi perizinan pemanfaatan ruang laut dilakukan pada bulan Maret 2019 oleh OPD bertempat di Kantor Camat Maratua dengan mengundang OPD lingkup Provinsi Kalimantan Timur dan Kabupaten Berau, pelaku usaha, dan perangkat kampung/desa. Pada sosialisasi ini, pelaku usaha yang hadir sebanyak 2 (dua) orang. Menurut Erlangga (2018), sedikitnya peserta sosialisasi antara lain sulitnya menentukan waktu yang tepat dan sulitnya mengumpulkan masyarakat karena masyarakat memiliki kepentingan masing-masing, pemahaman masyarakat mengenai kegunaan izin masih kurang, dan metode yang digunakan hanya sebatas pemaparan.

2. Identifikasi pemanfaatan dan perizinan pemanfaatan ruang laut dilakukan bulan Maret sampai denganApril 2019 dengan mendapatkan data setiap orang yang memanfaatkan ruang laut, perizinan, kesesuaian ruang dengan Rencana Zonasi KSNT Pulau Maratua, dan kegiatan yang merusak ekosistem.

3. Pengambilan keterangan dilakukan pada bulan Oktober 2019 dengan melakukan pengambilan keterangan kepada 15 (lima belas) pelaku usaha kegiatan wisata bahari yang telah memanfaatkan ruang laut dan seluruhnya diwajibkan menandatangani surat pernyataan kesanggupan untuk mengurus izin lokasi perairan.

4. Identifikasi pemanfaatan ruang laut dilakukan pada bulan Desember 2019 dengan mendapatkan data yang lebih detail mengenai pemanfaatan ruang laut, keberadaaan masyarakat lokal, kondisi ekosistem, dan memantau perkembangan permohonan izin lokasi perairan.

5. Pembukaan pelayanan PTSP DJPRL KKP di Pulau Maratua dilakukan pada $23-27$ Desember 2019 yang bertujuan untuk lebih mendekatkan pelayanan dan memberikan kemudahan untuk pelaku usaha dalam melakukan konsultasi dan memohonkan izin lokasi perairan. Sistem pelayanan perizinan jemput bola langsung ke lapangan telah dilakukan oleh DJPT dengan program gerai perizinan yang merupakan implementasi dari Peraturan Menteri Kelautan dan Perikanan Nomor 11/PERMEN-KP/2016 tentang standar pelayanan minimum gerai perizinan kapal penangkap ikan hasil pengukuran ulang. Izin yang diterbitkan berupa Surat Izin Usaha Perikanan (SIUP), Buku Kapal Perikanan (BKP), Surat Izin Penangkapan Ikan (SIPI), dan Surat Izin Kapal Pengangkut Ikan (SIKPI). Penyelenggaraan gerai perizinan di tahun 2016 dilakukan di 32 (tiga puluh dua) lokasi dengan total PNBP sebesar Rp86.000.000.000,00 meliputi sebanyak 1.153 SIUP, 1.007 SIPI, 44 SIKPI, dan 1.019 BKP (Kementerian Kelautan dan Perikanan, 2017).

Tabel 3 menunjukan bahwa semua responden (100\%) sudah mengetahui mengenai adanya kewajiban pengurusan izin lokasi perairan di KSNT Pulau Maratua. Semua responden $(100 \%)$ juga mengetahui bahwa kewenangan pemberian izin lokasi perairan di KSNT Pulau Maratua adalah Menteri Kelautan dan Perikanan. Pelaku usaha bersedia mengurus izin lokasi perairan, dan mereka juga telah memiliki Nomor Induk Berusaha (NIB) dari Sistem Online Single Submission (OSS) hanya sebesar $46,7 \%$ (7 pelaku usaha) karena sebagian besar pelaku usaha belum mengetahui OSS dengan jelas. Pelaku usaha bersedia menyampaikan permohonan izin lokasi perairan kepada PTSP DJPRL KKP di Jakarta sebanyak 86,7\% (13 pelaku usaha). Selanjutnya, sebanyak $93,3 \%$ (14 pelaku usaha) bersedia membayar PNBP ketika telah diterbitkan izin lokasi perairan.

\section{KONTRIBUSI IZIN LOKASI PERAIRAN KEGIATAN WISATA BAHARI TERHADAP PNBP KKP}

Pembayaran PNBP dilakukan setelah Menteri Kelautan dan Perikanan menyetujui izin lokasi perairan untuk kegiatan wisata bahari. Pelaku usaha akan diberikan bukti tagihan PNBP untuk dibayarkan. Dalam hal ini, Pulau Maratua termasuk sebagai RIPPARNAS dan tarif izin lokasi perairan kegiatan wisata bahari per hektare dikenakan biaya sebesar Rp30.000.000,00.

Selama periode April 2019 sampai dengan Maret 2020, Menteri Kelautan dan Perikanan 
Tabel 3. Rekapitulasi Hasil Wawancara dengan Pelaku Usaha Wisata Bahari Tahun 2020.

\begin{tabular}{|c|c|c|c|c|c|c|c|c|c|c|c|c|}
\hline \multirow{3}{*}{ Pelaku Usaha } & \multicolumn{12}{|c|}{ Wawancara } \\
\hline & \multicolumn{2}{|c|}{$\mathbf{I}$} & \multicolumn{2}{|c|}{ II } & \multicolumn{2}{|c|}{ III } & \multicolumn{2}{|c|}{ IV } & \multicolumn{2}{|c|}{$\mathbf{V}$} & \multicolumn{2}{|c|}{ VI } \\
\hline & $\mathbf{Y}$ & $\mathbf{T}$ & $\mathbf{Y}$ & $T$ & $\mathbf{Y}$ & $T$ & $\mathbf{Y}$ & $T$ & $\mathbf{Y}$ & $\mathbf{T}$ & $\mathbf{Y}$ & $\mathbf{T}$ \\
\hline PT Pondok Wisata & $\sqrt{ }$ & & $\sqrt{ }$ & & $\sqrt{ }$ & & & $\sqrt{ }$ & & $\sqrt{ }$ & & $\sqrt{ }$ \\
\hline PT Maratua Paradise & $\sqrt{ }$ & & $\sqrt{ }$ & & $\sqrt{ }$ & & $\sqrt{ }$ & & $\sqrt{ }$ & & $\sqrt{ }$ & \\
\hline PT Noah Maratua Resor & $\sqrt{ }$ & & $\sqrt{ }$ & & $\sqrt{ }$ & & $\sqrt{ }$ & & $\sqrt{ }$ & & $\sqrt{ }$ & \\
\hline PT Pratasaba Apta Astama & $\sqrt{ }$ & & $\sqrt{ }$ & & $\sqrt{ }$ & & $\sqrt{ }$ & & $\sqrt{ }$ & & $\sqrt{ }$ & \\
\hline PT Maratua Island Diving Resort & $\sqrt{ }$ & & $\sqrt{ }$ & & $\sqrt{ }$ & & & $\sqrt{ }$ & $\sqrt{ }$ & & $\sqrt{ }$ & \\
\hline PT Jade Homestay & $\sqrt{ }$ & & $\sqrt{ }$ & & $\sqrt{ }$ & & $\sqrt{ }$ & & $\sqrt{ }$ & & $\sqrt{ }$ & \\
\hline PT Surga Hijau Lestari & $\sqrt{ }$ & & $\sqrt{ }$ & & $\sqrt{ }$ & & $\sqrt{ }$ & & $\sqrt{ }$ & & $\sqrt{ }$ & \\
\hline PT Maratua Camp & $\sqrt{ }$ & & $\sqrt{ }$ & & $\sqrt{ }$ & & & $\sqrt{ }$ & $\sqrt{ }$ & & $\sqrt{ }$ & \\
\hline PT Maratua Seaview Resort & $\sqrt{ }$ & & $\sqrt{ }$ & & $\sqrt{ }$ & & & $\sqrt{ }$ & $\sqrt{ }$ & & $\sqrt{ }$ & \\
\hline PT Paradina Adya Sandika & $\sqrt{ }$ & & $\sqrt{ }$ & & $\sqrt{ }$ & & $\sqrt{ }$ & & $\sqrt{ }$ & & $\sqrt{ }$ & \\
\hline PT Tanjung Dewata Resort & $\sqrt{ }$ & & $\sqrt{ }$ & & $\sqrt{ }$ & & & $\sqrt{ }$ & & $\sqrt{ }$ & $\sqrt{ }$ & \\
\hline Virgin Cocoa Tropical Hideaway Island & $\sqrt{ }$ & & $\sqrt{ }$ & & $\sqrt{ }$ & & & $\sqrt{ }$ & $\sqrt{ }$ & & & \\
\hline Nunukan Island Resort & $\sqrt{ }$ & & $\sqrt{ }$ & & $\sqrt{ }$ & & & $\sqrt{ }$ & $\sqrt{ }$ & & $\sqrt{ }$ & \\
\hline PT Maratua Nusa Sentosa & $\sqrt{ }$ & & $\sqrt{ }$ & & $\sqrt{ }$ & & & $\sqrt{ }$ & $\sqrt{ }$ & & $\sqrt{ }$ & \\
\hline PT Nabucco Island & $\sqrt{ }$ & & $\sqrt{ }$ & & $\sqrt{ }$ & & $\sqrt{ }$ & & $\sqrt{ }$ & & $\sqrt{ }$ & \\
\hline Jumlah & 15 & 0 & 15 & 0 & 15 & 0 & 7 & 8 & 13 & 2 & 14 & 1 \\
\hline
\end{tabular}

Keterangan: Ya (Y) dan Tidak ( $\mathrm{T})$

Sumber: Data primer diolah, 2020

telah menerbitkan sebanyak 6 (enam) izin lokasi perairan dengan nilai PNBP sebesar Rp238.200.000,00 (Tabel 4). Hal ini menunjukkan bahwa hanya $40 \%$ dari total pelaku usaha yang membayar PNBP. Sesuai dengan Rencana Zonasi KSNT Pulau Maratua dalam peraturan pemanfaatan ruang, kegiatan wisata bahari dapat dilakukan di Kawasan Pemanfaatan Umum (KPU), yaitu Zona Perikanan Budidaya seluas 1.698,28 ha, Zona Pelabuhan seluas 1.862,52 ha, dan di Kawasan Konservasi Pesisir dan PulauPulau Kecil (KKP3K) seluas 70.136,22 ha. Adapun total keseluruhan seluas 73.697,02 ha. Apabila kegiatan wisata bahari memanfaatkan $1 \%$ dari total keseluruhan luasan maka akan diperoleh lahan seluas 736,97 ha. Hal ini menunjukkan kontribusi izin lokasi perairan terhadap PNBP KKP baru mencapai 1,1\% (seluas 7,94 ha) pada periode April 2019 sampai Maret 2020.

Rendahnya kontribusi izin lokasi perairan dapat ditingkatkan dengan upaya-upaya berikut, yaitu;

1. Penyadartahuan dan pembinaan kepada pelaku usaha yang lebih intensif, khususnya pemberian kemudahan perizinan, seperti dilakukan secara online atau membuka gerai perizinan di Pulau Maratua.

2. Perbaikan inovasi dan kualitas pelayanan perizinan serta sarana dan prasarana.

3. Peningkatan kompetensi sumber daya manusia terkait pelayanan dan teknis pemberian izin.

Tabel 4. Izin Lokasi Perairan yang Diterbitkan oleh Menteri Kelautan dan Perikanan Periode April 2019 sampai dengan Maret 2020.

\begin{tabular}{lccc}
\hline \multicolumn{1}{c}{ Pelaku Usaha } & Tarif PNBP (Rupiah) & Luasan (Ha) & Nilai PNBP (Rupiah) \\
\hline PT Maratua Paradise & $30.000 .000,00$ & 4,15 & $124.500 .000,00$ \\
PT Pratasaba Apta Astama & $30.000 .000,00$ & 0,89 & $26.700 .000,00$ \\
PT Surga Hijau Lestari & $30.000 .000,00$ & 0,94 & $28.200 .000,00$ \\
PT Paradina Adya Sandika & $30.000 .000,00$ & 0,15 & $4.500 .000,00$ \\
PT Maratua Nusa Sentosa & $30.000 .000,00$ & 0,77 & $23.100 .000,00$ \\
PT Noah Maratua Resor & $30.000 .000,00$ & 1,04 & $31.200 .000,00$ \\
\hline TOTAL & & $\mathbf{7 , 9 4}$ & $\mathbf{2 3 8 . 2 0 0 . 0 0 0 , 0 0}$
\end{tabular}

Sumber: Pelayanan Terpadu Satu Pintu DJPRL KKP, 2020 
4. Pengelolaan PNBP mulai dari tahap perencanaan, pelaksanaan dan penatausahaan, serta pengawasan dan pelaporan.

5. Menetapkan target dan mengoptimalkan realisasi PNBP.

6. Pemberian sanksi sesuai peraturan perundang undangan untuk pelaku usaha yang tidak mengurus dan memiiki izin lokasi perairan.

Nursanti, Mas'ud, \& Alam (2019) berpendapat bahwa meskipun pelayanan telah sesuai dengan Standar Operasional Prosedur (SOP) mulai dari jenis pelayanan, tarif yang ditentukan, jangka waktu penyelesaian dan persyaratan yang ditetapkan, dan secara keseluruhan pengelolaan PNBP pada kantor pertanahan Kota Makassar cukup efektif, namun diperlukan perbaikan dalam segala aspek, yaitu sistem pelayanan, sarana dan prasarana, sumber daya manusia, perencanaan anggaran, pelaksanaan dan pengawasan, inovasi pelayanan untuk percepatan kegiatan pelayanan pertanahan. Walelang, Alexander, \& Tangkuman (2017) juga sepakat untuk terus meningkatkan kinerja pemungutan PNBP bea lelang agar menetapkan sanksi bagi pembeli-pembeli lelang yang melakukan pelanggaran, meskipun tetap masuk ke kas negara, namun hal ini bisa mempengaruhi potensi penerimaan bea lelang.

\section{PENUTUP}

Pulau Maratua merupakan salah satu PPKT berpenduduk yang terletak di Laut Sulawesi dengan Titik Dasar TD.039 dan Titik Referensi TR.039. Tingginya keanekaragaman hayati laut perairan Pulau Maratua merupakan daya tarik bagi para pelaku usaha untuk melakukan investasi wisata bahari khususnya pembangunan resort. Pelaku usaha yang memohonkan izin lokasi perairan sebanyak 7 (tujuh) atau $47 \%$, hal ini menyebabkan rendahnya capaian PNBP KKP dengan nilai Rp238.200.000,00 berasal dari 6 (enam) izin lokasi perairan yang telah diterbitkan oleh Menteri Kelautan dan Perikanan. Secara keseluruhan, kegiatan yang dilakukan KKP untuk meningkatkan pemahaman pelaku usaha dengan melakukan sosialisasi perizinan pemanfaatan ruang laut, pengambilan keterangan, dan pembukaan loket pelayanan perizinan di Pulau Maratua belum cukup untuk meningkatkan kontribusi PNBP KKP. Oleh karena itu, peningkatan kontribusi izin lokasi perairan kegiatan wisata bahari diperlukan upaya sosialisasi dan pembinaan yang lebih intensif, perbaikan inovasi dan kualitas pelayanan perizinan serta sarana dan prasarana, peningkatan kompetensi sumber daya manusia, pengelolaan PNBP, menetapkan target dan optimalisasi realisasi PNBP, dan pemberian sanksi.

\section{UCAPAN TERIMA KASIH}

Ucapan terima kasih penulis sampaikan kepada Direktorat Perencanaan Ruang laut yang telah memberikan pendanaan pada kegiatan penelitian ini. Ucapan terima kasih juga penulis sampaikan kepada Pelayanan Terpadu Satu Pintu DJPRL KKP, Direktorat Jenderal Pengawasan Sumber Daya Kelautan dan Perikanan, Pemerintah Kabupaten Berau yang telah membantu dalam hal data dan informasi selama kegiatan penelitian ini berlangsung.

\section{PERNYATAAN KONTRIBUSI PENULIS}

Dengan ini kami menyatakan bahwa kontribusi masing-masing penulis terhadap pembuatan karya tulis adalah: Didit Eko Prasetiyo sebagai kontributor utama, Uswatun Chasanah, Muhandis Sidqi, Budi Muhammad Ruslan, Gustiawirman, dan Suraji sebagai kontributor anggota.

\section{DAFTAR PUSTAKA}

Angraini, M., Amir, A.M, \& Yusnita, N. (2018). Pengelolaan Penerimaan Negara Bukan Pajak: Suatu Tinjauan Evaluatif (Studi pada Satuan Kerja Pertanahan Kabupaten Parigi Moutong). Katalogis, 6, 23-34. Diperoleh dari http://jurnal.untad.ac.id/jurnal/ index.php/Katalogis/article/view/11413

Arrum, D.A. (2019). Kepastian Hukum Dalam Perizinan Berusaha Terintegrasi Secara Elektronik (Online Single Submission) di Indonesia. Jurist-Diction, 2(5), 1631-1654. Diperoleh dari https://e-journal. unair.ac.id/JD/article/view/15222/8268

Astuti, R.Y., Budisusanto, Y., Pratomo, D.G, \& Sidqi, M. (2018). Analisa Kesesuaian RZWP-3-K dengan Eksisting Penggunaan Ruang Laut Berdasarkan UU. No. 1 Tahun 2014 dan Permen-KP No. 23 Tahun 2016. Jurnal Teknik ITS, Vol 7(1), 2337-3520. doi: 10.12962/j23373539. v7i1.28559

Budi, R., \& Handayani, N. (2019). Pengendalian Internal Penerimaan Negara Bukan Pajak di Taman Nasional Bali Barat. e-Journal Ekonomi Bisnis dan Akuntansi, 6(1), 97-101. doi: https://doi. org/10.19184/ejeba.v6i2.11146 
Badan Perencana Penelitian dan Pengembangan Kabupaten Berau. (2019). Perubahan Atas RPJMD Kabupaten Berau Tahun 2016-2021. Tanjung Redep, ID: BP3 Berau

Badan Pusat Statistik. (2020). Realisasi Pendapatan Negara (Milyar Rupiah), 2007-2020, (update terakhir 10 Januari 2020). Diperoleh dari https:// www.bps.go.id/statictable/2009/02/24/1286/ realis a si-pendapatan-negara-milyar-rupiah-2007-2020.html

Djou, J.A.G. (2013). Pengembangan 24 Destinasi Wisata Bahari Kabupaten Ende. Jurnal IImiah Sosial dan Humaniora Kawistara, 3(1), 1-116. doi: https:// doi.org/10.22146/kawistara.3958

Direktorat Perencanaan Ruang Laut. (2019). Identifikasi Pemanfaatan dan Perizinan Pemanfaatan Ruang Laut Pulau Maratua dan Pulau Sambit. Jakarta, ID: Kementerian Kelautan dan Perikanan

Direktorat Jenderal Pengelolaan Ruang Laut. (2019). Infografis: Tata Cara Pemberian Izin Lokasi Perairan. Jakarta, ID: Kementerian Kelautan dan Perikanan

Direktorat Pendayagunaan Pesisir dan Pulau-Pulau Kecil. (2020). Direktori Pulau-Pulau Kecil Indonesia-Maratua. Direktorat Pendayagunaan Pulau-Pulau Kecil. Diperoleh dari http://www. ppk-kp3k.kkp.go.id/direktori-pulau/index.php/ public_c/pulau_info/298

Direktorat Jenderal Pengelolaan Ruang Laut. (2020). Laporan Kinerja Tahun 2019. Jakarta, ID: Kementerian Kelautan dan Perikanan

Ehler, C., Zaucha, J., \& Gee, K. (Ed.1) (2019). Maritime/ Marine Spatial Planning at the Interface of Research and Practice - Maritime Spatial Plannig past, present, future. Retrieved from https://www. palgrave.com/gp/book/9783319986951

Erlangga, D. (2018). Pelaksanaan Sosialisasi Pembuatan Izin Mendirikan Bangunan (IMB) Oleh Dinas Penanaman Modal, Pelayanan Terpadu Satu Pintu, Koperasi UMKM dan Perdagangan Kabupaten Pangandaran. Jurnal IImu Administrasi Negara, 5(1). Diperoleh dari https://jurnal. unigal.ac.id/index.php/dinamika/article/ view/1221/1080

Idris, Prastowo, M., \& Rahmat, B. (2019). Kondisi Ekosistem Terumbu Karang di Lokasi dan Bukan Lokasi Penyelaman Pulau Maratua. Jurnal Kelautan Nasional, 14(1), 59-69. doi: http:// dx.doi.org/10.15578/jkn.v14i1.6898

Kementerian Kelautan dan Perikanan. (2017). Tahun 2017 KKP Kembali Buka Gerai Perizinan di 30 Lokasi. Diperoleh dari https://news.kkp.go.id/ index.php/tahun-2017-kkp-kembali-buka-geraiperizinan-di-30-lokasi/
Kementerian Kelautan dan Perikanan. (2018). Laporan Keuangan (Audited). Jakarta, ID: Kementerian Kelautan dan Perikanan

Kementerian Pariwisata. (2018). Studi Penyusunan Rencana Operasional Pengembangan $3 \mathrm{~A}$ di KSPN Derawan-Sangalaki dan Sekitarnya Provinsi Kalimantan Timur. Jakarta, ID: Asdep Pengembangan Destinasi Regional II Area IV

Mellawati, J., Fepriadi, Yarianto, \& Laddade, T. (2010). Identifikasi keanekaragaman flora dan fauna Berau Kalimantan Timur pada kegiatan pra survei tapak PLTN. Jurnal Pengembangan Energi Nuklir, (12)2, 66-74. doi: http://dx.doi.org/10.17146/ jpen.2010.12.2.1449

Nursanti, Mas'ud, M, \& Alam, N. (2019). Efektifitas dan pengelolaan penerimaan negara bukan pajak (studi kasus pada Kantor Pertanahan Kota Makassar tahun 2015-2018). Paradoks: Jurnal IImu Ekonomi, 2(4), 97-109. Diperoleh dari http:// jurnal.fe.umi.ac.id/index.php/PARADOKS/article/ view/299

Orams, M.B. (1999). Impact and Marine Tourism. Development Management. London, UK: Routledge

Priyono, B. (2016). Perizinan sebagai sarana pengendalian pemanfaatan ruang dalam perspektif pemanfaatan ruang di daerah. Jurnal Ilmiah Administrasi Pemerintahan Daerah, 8(2), 16-37. Diperoleh dari http://ejournal.ipdn.ac.id/ JAPD/article/view/187

Panjaitan, J.Y, Mujiburrahman, \& Effendi, S.A. (2019). Perkembangan Realisasi Penerimaan Negara Bukan Pajak Sumber Daya Alam (PNBP SDA). Jakarta, ID: Pusat Kajian Anggaran, Badan Keahlian, Dewan Perwakilan Rakyat Republik Indonesia

Pelayanan Terpadu Satu Pintu DJPRL KKP. (2020). Laporan Pelayanan Perizinan Pemanfaatan Ruang Laut di Pulau Maratua. Jakarta, ID: Kementerian Kelautan dan Perikanan

Peraturan Menteri Kelautan dan Perikanan Nomor 24/ PERMEN-KP/2019 tentang Tata Cara Pemberian Izin Lokasi Perairan dan Izin Pengelolaan Perairan di Wilayah Pesisir dan Pulau-Pulau Kecil

Peraturan Menteri Kelautan dan Perikanan Nomor 4/ PERMEN-KP/2018 tentang Rencana Zonasi Kawasan Strategis Nasional Tertentu Pulau Maratua dan Pulau Sambit di Provinsi Kalimantan Timur Tahun 2018-2037

Peraturan Pemerintah Nomor 75 Tahun 2015 tentang Jenis dan Tarif Atas Jenis Penerimaan Negara Bukan Pajak Yang Berlaku Pada Kementerian Kelautan dan Perikanan 
Peraturan Pemerintah Nomor 50 Tahun 2011 tentang Rencana Induk Pembangunan Kepariwisataan Nasional Tahun 2010-2025

Robby, U. B., \& Tarwini, W. (2019). Inovasi pelayanan perizinan melalui Online Single Submission (OSS): Studi pada izin usaha di Dinas Penanaman Modal dan Pelayanan Terpadu Satu Pintu (DPMPTSP Kabupaten Bekasi). Jurnal IImiah Administrasi Publik dan Pembangunan, 10(2), 51-57. doi: https://doi.org/10.23960/administratio. v10i2.98

Sugiarto, A. (2017). Implementasi pengendalian pemanfaatan ruang dan sanksi administratif dalam rencana tata ruang wilayah Kabupaten Sidoarjo. Jurnal Kebijakan dan Manajemen Publik, 5(1), 41-60. doi: https://doi.org/10.21070/ jkmp.v5i1.812

Sidqi, M., Suharyanto., Astuti, R.Y., \& Ardarini, F. (2018). Analisis kesesuaian rencana zonasi kawasan strategis nasional tertentu terhadap pemanfaatan ruang laut eksisting sektor wisata bahari di pulau kecil terluar studi kasus di Pulau Maratua, Kabupaten Berau. Prosiding Seminar Nasional Geomatika, 957-964. doi http://dx.doi. org/10.24895/SNG.2018.3-0.1062

Supriyatno \& Budi. (2009). Manajemen Tata Ruang. Tangerang, ID: CV Media Berlian

Sekaran, U. (2011). Metode Penelitian IImiah. Jakarta, ID: Salemba Empat

Sutendi, N.L. (2019). Analisis Implementasi Perizinan Berbasis Online OSS (Online Single Submission) Bagi Penanaman Modal di Indonesia. Diperoleh dari https://www.researchgate.net/ publication/337864291_Analisis_Implementasi_ Perizinan_Berbasis_Online_OSS_Online_ Single_Submission_Bagi_Penanaman_Modal_ Di_Indonesia

Undang-Undang Nomor 1 Tahun 2014 Tentang Perubahan Atas Undang-Undang Nomor 27 Tentang Pengelolaan Wilayah Pesisir dan Pulau-Pulau Kecil

Walelang, R.P.A, Alexander, S., \& Tangkuman, S. (2017). Analisis efektifitas penatausahaan Penerimaan Negara Bukan Pajak (PNBP) pada Kantor Pelayanan Kekayaan Negara dan Lelang (KPKNL) Manado. Jurnal Riset Ekonomi Manajemen, Bisnis dan Akuntansi. 5(2), 2647-2655. doi: https://doi.org/10.35794/emba. v5i2.17103

Yunia, S. (2016). Izin lokasi sebagai syarat perolehan hak atas tanah dalam penyelenggaraan pembangunan prumahan. Skripsi. Lampung, ID: Fakultas Hukum, Universitas Lampung
Yustinaningrum, D. (2017). Pengembangan wisata bahari di Taman Wisata Perairan Pulau Pieh dan laut sekitarnya. Jurnal IImu-IImu Pertanian Agrika. 11(1), 96-111. Diperoleh dari http:// publishing-widyagama.ac.id/ejournal-v2/index. php/agrika/article/view/455/444 